\title{
Multidimensional Dyspnea Profile: an instrument for clinical and laboratory research
}

\author{
Robert B. Banzett ${ }^{1,2}$, Carl R. O'Donnell ${ }^{1,2}$, Tegan E. Guilfoyle ${ }^{1}$, \\ Mark B. Parshall ${ }^{3}$, Richard M. Schwartzstein ${ }^{1,2}$, Paula M. Meek ${ }^{4}$, \\ Richard H. Gracely ${ }^{5}$ and Robert W. Lansing ${ }^{1}$
}

Affiliations:

${ }^{1}$ Division of Pulmonary, Critical Care \& Sleep Medicine, Beth Israel Deaconess Medical Center, Boston, MA, USA.

${ }^{2}$ Department of Medicine, Harvard Medical School, Boston, MA, USA.

${ }^{3}$ College of Nursing, University of New Mexico, Albuquerque, NM, USA.

${ }^{4}$ College of Nursing, University of Colorado, Denver, Aurora, CO, USA.

${ }^{5}$ Department of Endodontics, UNC School of Dentistry, Center for Neurosensory Disorders, University of North Carolina, Chapel Hill, NC, USA.

Correspondence: Robert B. Banzett, Division of Pulmonary and Critical Care KSB-26, Beth Israel Deaconess Medical Center, 330 Brookline Ave, Boston, MA 02215-5491, USA. E-mail: rbanzettabidmc.harvard.edu

ABSTRACT There is growing awareness that dyspnoea, like pain, is a multidimensional experience, but measurement instruments have not kept pace. The Multidimensional Dyspnea Profile (MDP) assesses overall breathing discomfort, sensory qualities, and emotional responses in laboratory and clinical settings. Here we provide the MDP, review published evidence regarding its measurement properties and discuss its use and interpretation. The MDP assesses dyspnoea during a specific time or a particular activity (focus period) and is designed to examine individual items that are theoretically aligned with separate mechanisms. In contrast, other multidimensional dyspnoea scales assess recalled recent dyspnoea over a period of days using aggregate scores.

Previous psychophysical and psychometric studies using the MDP show that: 1) subjects exposed to different laboratory stimuli could discriminate between air hunger and work/effort sensation, and found air hunger more unpleasant; 2) the MDP immediate unpleasantness scale (A1) was convergent with common dyspnoea scales; 3) in emergency department patients, two domains were distinguished (immediate perception, emotional response); 4) test-retest reliability over hours was high; 5) the instrument responded to opioid treatment of experimental dyspnoea and to clinical improvement; 6) convergent validity with common instruments was good; and 7) items responded differently from one another as predicted for multiple dimensions.

@ERSpublications

The Multidimensional Dyspnea Profile provides a unified, reliable instrument for both clinical and laboratory research http://ow.ly/Ix8ic

Editorial comment in Eur Respir J 2015; 45: 1526-1528 [DOI: 10.1183/09031936.00030115].

This article has supplementary material available from erj.ersjournals.com.

Received: Feb 262014 | Accepted after revision: Dec 192014 | First published online: March 182015

Support statement: Supported by NIH grant NR10006.

Funding information for this article has been deposited with FundRef.

Conflict of interest: Disclosures can be found alongside the online version of this article at erj.ersjournals.com

Copyright OERS 2015. ERJ Open articles are open access and distributed under the terms of the Creative Commons Attribution Non-Commercial Licence 4.0. 


\section{Introduction}

Dyspnoea is characterised as "a subjective experience of breathing discomfort that consists of qualitatively distinct sensations that vary in intensity [and] vary in their unpleasantness and in their emotional and behavioral significance" [1]. There is increasing recognition that dyspnoea is a multidimensional experience, and that at least some of the dimensional variation results from different afferent mechanisms [2-4]. This complexity is not evaluated adequately by current measurement methods for the assessment of dyspnoea, and it is often difficult to compare results between laboratory and clinical studies because they typically use different dyspnoea instruments. Therefore, we developed the Multidimensional Dyspnea Profile (MDP), an instrument that can be used in both laboratory and clinical research settings. Here we 1) describe the MDP and its theoretical foundation, 2) review previously published information regarding its validity and reliability, and 3) present new information regarding the instrument. In the online supplementary material, we include the complete MDP together with a history of its development and a detailed guide for users.

\section{Theoretical foundation and MDP content: background of multidimensional measurement}

The dyspnoea instruments most commonly used in clinical and epidemiologic research (reviewed in [5-7]) are primarily questionnaires that assess recent history of activity-related dyspnoea or the extent to which dyspnoea limits activities (e.g., the Medical Research Council breathlessness scale (MRC) and the Baseline/ Transitional Dyspnea Index (BDI/TDI) [8, 9]). These instruments provide very useful information but were developed to assess the usual impact of dyspnoea on activity over a period of days or weeks based on recall. Measures of activity-related dyspnoea impact or burden are generally developed for purposes such as disability assessment or serial clinical assessment in outpatient settings. None was developed or validated for use in experimentally induced or acute clinical dyspnoea; in fact, most would not make semantic sense if used, for example, to assess dyspnoea during a particular experimental intervention, or at the completion of a 6-min walk test.

Most experimental studies and a limited number of clinical studies in acute settings have utilised unidimensional ratings to measure dyspnoea at a specific time. These scales have taken various forms, such as visual analogue scales (VAS) [10-12], numerical rating scales (NRS) [13-15], or various modifications of Borg scales [16-20]. All have shown reproducible results when a consistent instruction set is given to the subjects $[6,11,13,15,21-25]$. However, instruction scripts and scale formats have varied between laboratories and even within laboratories. The perceptual dimension rated differs across studies (e.g., "breathing difficulty" may not equate to "breathing discomfort"), and is often not defined clearly in publications. Unidimensional scales can capture the overall severity of dyspnoea at a particular time-point (current or recalled), but do not capture information about the quality of breathing discomfort, its unpleasantness or the associated emotional responses.

We based the MDP on a conceptual model that has been extensively used to better understand the experience of pain [26-28]. Pain has long been recognized as a multidimensional experience, and multidimensional instruments have been used to measure pain for 4 decades [29,30], with increasing sophistication [27, 31-35]. Multidimensional pain assessment has advanced pain research and treatment, and has enabled translation between laboratory studies, clinical research and the bedside. There is increasing realisation that dyspnoea, too, is a multidimensional experience and that at least some of the dimensional variation results from different afferent mechanisms. The conceptual model as adapted for dyspnoea is shown in figure 1.

The MDP was designed to be useful in both laboratory and clinical research, allowing better translation between laboratory and clinical findings. The theoretical constructs embodied by the instrument may be useful to clinicians evaluating dyspnoea at the bedside as well. Prior to development of the MDP, no single instrument comprehensively assessed immediate discomfort, sensory quality (SQ) and emotional impact of dyspnoea in a manner equally relevant to experimental subjects and patients.

\section{Introduction to the MDP}

The MDP rests on years of converging clinical and laboratory research from several groups on the language and measurement of dyspnoea. Key experiments contributing to the development of the elements of the instrument are described below. The complete version of the MDP with page-by-page description (Section S1 in the online supplementary material) reflects its evolution based on laboratory and clinical studies (described in Section S2 in the online supplementary material). In addition to the psychometric approach usually used to validate such instruments, we have also employed psychophysical methods to provide additional validation (this dual approach is discussed further in Section S3 in the online supplementary material). 


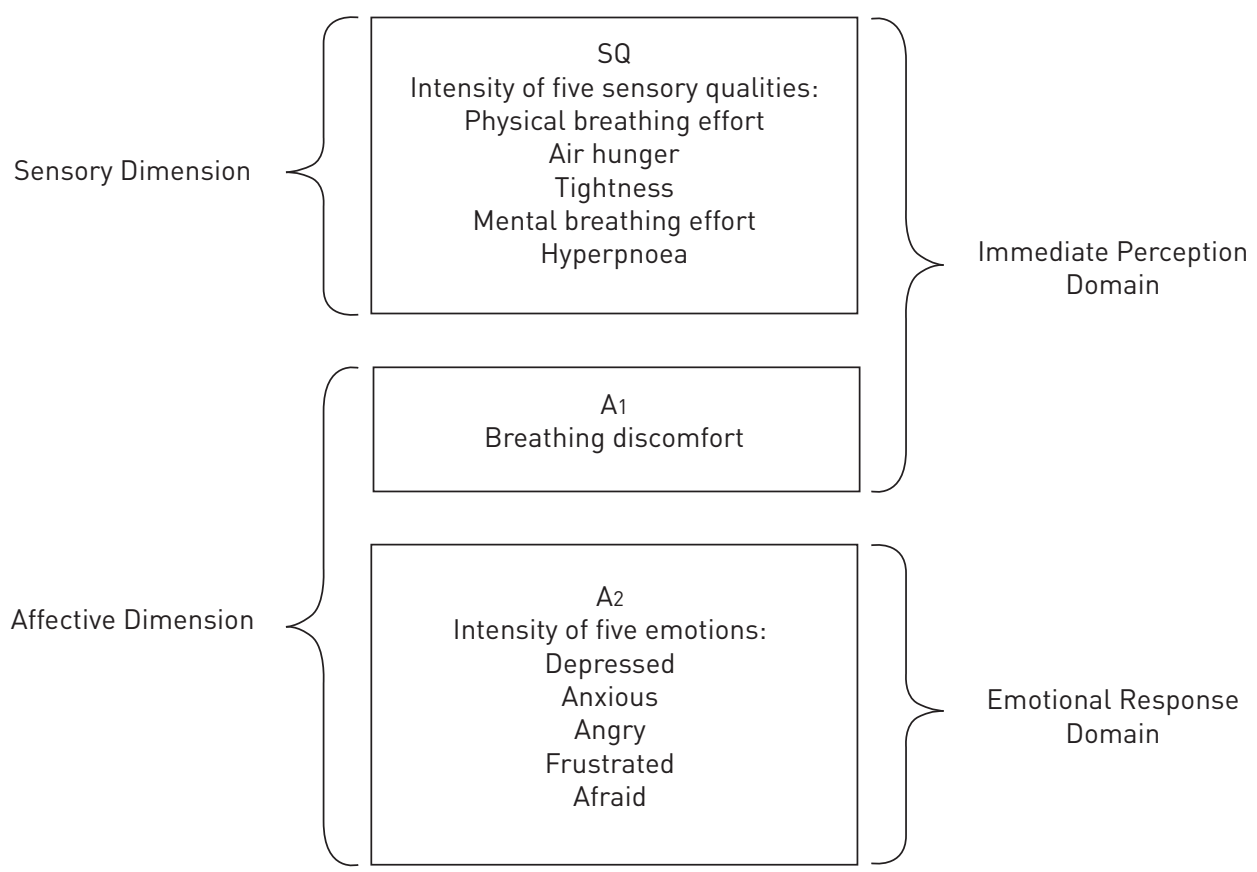

FIGURE 1 Model of the components of dyspnoea underlying the Multidimensional Dyspnea Profile. The division into sensory (SQ) and affective dimensions unpleasantness ( $\left.\mathrm{A}_{1}\right)$ and emotional response (A2) (shown on the left) is based on a well-developed conceptual model of pain perception [26]. The division into Immediate and Emotional Response Domains (shown on the right) is based on empirical evidence from emergency department patients [36].

\section{Content of the MDP}

The MDP is intended to refer to a specific event or time. The user must specify a "focus period", such as "after you climb three flights of stairs", "the last minute of breathing on the mouthpiece" or "right now".

\section{Overall breathing discomfort}

Affective: A1

The MDP uses a scale anchored by "neutral" and "unbearable" to obtain a rating of immediate "breathing discomfort/unpleasantness", wording that parallels the core of the American Thoracic Society (ATS) definition of dyspnoea as "a subjective experience of breathing discomfort" [1]. This immediate discomfort is analogous to the immediate unpleasantness of pain, which is more primal than evaluative/emotional responses and causes immediate avoidance behaviours [33].

\section{Dyspnoea quality}

Sensory quality: SQ

A significant advance in pain measurement came with pain questionnaires that included scales for pain qualities such as stabbing, burning, aching, etc. [37, 38]. The various qualities of respiratory sensation have been the target of a number of studies, often referred to as studies of the "language of dyspnoea". The principal sensory dimensions of respiratory discomfort have been shown to have different neural circuitry (reviewed in [1]). Descriptions of dyspnoea, collected from patients, and laboratory studies have been used by several groups to develop arrays of up to 45 sensory descriptors of dyspnoea from which subjects could choose descriptors appropriate for their own experience [39-51]. An important outcome of such studies is that one can identify terms that can be grouped together based on cluster analysis or factor analysis.

Discomfort and emotions are commonly discussed in daily life, and most people find it easy to distinguish among them and to scale them quantitatively. Describing the individual sensations of respiratory discomfort is, however, unfamiliar territory; most people find it harder to describe exactly what breathing sensation they feel. Providing descriptors to select or to scale has been used to address this problem $[43-48,52,53]$.

The MDP was designed to group highly related terms into single items; each SQ grouping appears only once. Item groupings used in the MDP are derived from groupings reproducibly identified in factor analytic studies $[48,49]$. In the MDP, the single appearance of each known SQ grouping simplifies the subject's rating task and simplifies analysis. Many patients and research subjects do not have a precise 
language for describing the qualities of breathing sensations, but they recognise the descriptors used in the MDP and make appropriate endorsements $[4,36]$.

To strengthen the assessment of sensory qualities, the MDP employs both forced selection and rating scales to assess dyspnoea qualities. An advantage of forcing subjects to select descriptors is that the subjects themselves must decide whether the sensation was noticeable and, more importantly, must decide which sensation was the most apt description. Forced selection also controls for response biases such as reticence to provide any description or response "verbosity" in choosing all that are provided. On the other hand, scaling the intensity of perceptions allows data to be analysed with statistical tools such as correlation, regression and factor analysis.

\section{Emotional response to dyspnoea}

Affective: A2

Respiratory sensations, particularly intense air hunger or suffocation, can provoke powerful emotional responses that motivate adaptive behaviour, such as seeking medical attention, or maladaptive behaviour, such as avoidance of activity, which can result in physiological deconditioning and reduced quality of life. Similar visual analogue and numerical scales have been used to measure perceived emotion for half a century $[10,54]$.

A few investigators have combined unidimensional dyspnoea scales (discomfort or difficulty of breathing) with a second scale intended to capture affective or emotional response, e.g., anxiety or distress [55-57]. These scale combinations were an important advance in the multidimensional measurement of dyspnoea. Using these scales, laboratory experiments showed that the quality of respiratory discomfort varied depending on the stimulus [52, 58-60].

The simple emotion scales used in the MDP have previously proven useful for assessing pain-related emotions [27, 61]. Emotional responses to dyspnoea have also received attention in the past [62, 63]. Several studies of dyspnoea have employed single-emotion VAS measurements, most often to assess anxiety or distress $[56,57]$.

\section{Published evidence on MDP reliability and validity}

Initial testing of the MDP utilised both psychophysical and psychometric testing approaches to examine reliability, validity, and responsiveness (see the online supplementary material for explanation of the attributes of each approach). Content validity of the MDP items is strong because each item is based on earlier studies in which clinical experts and patients evaluated their clarity and salience [27, 43, 44, 48]. In this section, we summarise briefly the published evidence on: 1) the ability of the MDP items to discriminate the components of dyspnoea; 2) its construct validity (i.e. whether it measures what it is supposed to measure); 3) its responsiveness; and 4) its internal consistency and test-retest reliability.

\section{Construct validity}

If the underlying constructs of the MDP are valid, one would expect it to be responsive to well-characterised stimuli and to treatments, namely that: 1) Al would respond in the appropriate direction and magnitude; 2) at least some of the SQ and A2 items would respond along with A1. One would also expect evidence of discrimination, namely that: 3) items would show a dispersion of ratings; and 4) some items would not respond to some stimuli or treatments.

\section{Ability to discriminate items and dimensions (psychophysical)}

In a study using an earlier version of the MDP, healthy subjects were exposed to two models of laboratory dyspnoea contrived to produce predominantly air hunger (mild hypercapnia during tidal volume limitation) versus predominantly work/effort (maximal voluntary hyperpnoea against a moderate inspiratory resistance). Subjects discriminated the sensation of air hunger from the sensation of work/ effort under these circumstances. In addition, for a given sensory intensity of dyspnoea, immediate unpleasantness $\left(\mathrm{A}_{1}\right)$ and anxiety $\left(\mathrm{A}_{2}\right)$ were markedly greater during air hunger than during the work/effort stimulus [4]. This study confirmed the concept underlying the MDP: separable components of dyspnoea can be measured reproducibly.

\section{Domain structure, responsiveness and reliability in emergency department patients}

(psychometric)

A preliminary version of the MDP was administered to 151 emergency department patients with a dyspnoea complaint and a variety of underlying diagnoses [36, 64]. Patients were enrolled as soon as possible, but usually after treatment was underway. Patients were asked at several time points during their emergency department stay to respond to the MDP with respect to 1) their dyspnoea "now" and 2) the 
dyspnoea they recalled experiencing when deciding to seek treatment. The instrument was administered again to 68 of these patients in a follow-up visit 4-6 weeks later.

Domain structure. Although the 11 rating scales in the MDP are meant to measure separate constructs, factor analysis identified two principal components ("domains") that accounted for most of the item variance in the MDP ratings of emergency department patients [64]. The "immediate perception" domain was comprised of all five SQ intensity ratings plus the unpleasantness rating ( $\left.A_{1}\right)$; the "emotional response" domain was comprised of all five emotion ratings (A2) (figure 1). Principal components analysis identifies groupings of items in a particular context of use but does not identify the underlying basis for the identified domain structure (e.g. items may group together because the items are intrinsically correlated or because the underlying circumstance, in this case an emergency department visit, drove ratings of items in the same direction). The two-domain structure identified in this study showed that $\mathrm{A} 1$ and the five SQ items were driven together, and the five emotional items were driven together in the specific instance of emergency department visits. This demonstrated that a minimum of two domains was necessary to describe dyspnoea, but does not imply that two domains will provide sufficient dimensionality in all circumstances.

Responsiveness to clinical change. Emergency department treatment usually improves the underlying cause of dyspnoea, providing an opportunity to test the responsiveness of the instrument. Both immediate perception and emotional response domains were highly responsive to clinical change in the emergency department. We found that MDP ratings significantly and progressively declined from enrolment to each of two subsequent administrations in the emergency department [52] and from the last measurement in the emergency department to a follow-up rating 4-6 weeks later [36].

Reliability. Internal consistency and test-retest reliability were excellent over the course of hours in the emergency department for both "now" MDP ratings and "recall" MDP ratings [36, 64], but test-retest reliability decreased substantially when patients were asked to recall the same event several weeks later. Convergent validity was established in the follow-up patients, as demonstrated by the significant correlation of both MDP domains with the Pulmonary Functional Status \& Dyspnea Questionnaire and the Medical Research Council breathlessness scale [36].

Convergent validity: agreement of A1 scale with online VAS in laboratory (psychometric)

VAS scales are well accepted for the measurement of dyspnoea within a given subject [65, 66]. Two laboratory studies have shown high correlation between MDP Al ratings obtained just after laboratory-induced dyspnoea and VAS ratings obtained continuously during laboratory dyspnoea $\left(\mathrm{r}^{2}=0.84\right.$, $\mathrm{p}<0.001$ and $\mathrm{r}^{2}=0.70, \mathrm{p}<0.001$, respectively) [67, 68]. Data from our laboratory show a high correlation between MDP A1 ratings and the commonly used modified Borg scale $\left(r^{2}=0.64, p<0.001\right.$; see section S4 in the online supplementary material).

\section{Discussion}

Summary

The MDP responds appropriately in the laboratory to known changes in physiological stimuli and to treatment, and in the emergency department to inferred change in clinical condition. The data show that the various items in the MDP do not simply track together, but respond differently to different stimuli or treatments. The items may not separate in all circumstances - in the emergency department patients, we found separation of immediate perception from emotion, but items within these groupings tended to track together. Test-retest reliability has been shown in previous work. Concurrent validity has been shown in prior work. We believe that the use of both psychophysical and psychometric approaches to validate the MDP is unique in the field of dyspnoea measurement instruments, and increases our confidence in the instrument.

\section{Usefulness}

The MDP was designed to provide greater detail about the quality and affective dimension of dyspnoea for both laboratory and clinical research. In addition, because it is not disease specific, the MDP is useful in mechanistic studies comparing patients with healthy controls as well as in clinical studies in which diagnoses are heterogeneous. There are circumstances in which measurement of a single item such as "breathing discomfort" may suffice; in these instances the Al scale from the MDP is one option. The instructions for this scale correspond with the ATS definition of dyspnoea, and, in practice, the scale correlates highly with the commonly used Borg scale (See section S4 in the online supplementary material). However, both laboratory studies and clinical trials can be enhanced by a more complete measurement that includes the quality of dyspnoea and emotional responses to breathing discomfort. For example, the following goals may benefit from use of the MDP: 
Translation between laboratory and clinical studies

Controllable laboratory dyspnoea interventions are essential to study neural mechanisms by determining the effect of neural lesions on dyspnoea $[41,42,69,70]$ and essential to imaging cerebral activity related to dyspnoea [71-74]. They are also a convenient and efficient means of evaluating the efficacy and mechanism of potential palliative treatments for dyspnoea [75-79].

Critics of laboratory dyspnoea studies have stated that laboratory-induced dyspnoea is not the same as clinical dyspnoea. This criticism is simplistic and potentially misleading. The MDP allows us to quantitatively assess the similarities and differences in sensory quality between dyspnoea in a particular laboratory model and dyspnoea in a particular clinical context. Such information may help improve laboratory models or may help clarify afferent mechanisms in patients. In addition to differences in sensory quality, one might expect the context of serious illness to alter the affective response to dyspnoea, particularly the evaluative/emotional component. The MDP has been used in one study to compare a model of laboratory dyspnoea with clinical dyspnoea [68], but much more remains to be done (See "MDP allows comparison across studies and settings" in section S5a in the online supplementary material).

\section{Understanding the mechanisms underlying therapeutic interventions}

A particular therapy might decrease a primary dyspnoea sensation (e.g. air hunger or breathing work) and thereby reduce emotional response or it might act directly on emotional response without affecting primary sensation. It is easy to see, for example, that measuring only the sense of breathing effort might lead one to miss such an effect, while measuring the broad concept of "shortness of breath" with a single scale might lead to conflicting results, depending on the definition of the scale given to the subjects and on the interpretation of the scale by the subjects $[80,81]$ (see section S5b in the online supplementary material).

Individual diagnosis and therapy

Some of the individual elements incorporated into the MDP have been proven useful in diagnosis and in evaluating responses to treatment [46, 81-83]. The MDP itself may prove to be useful in diagnosis, targeting therapy or measuring the effectiveness of treatment, but there is no evidence yet regarding its use in the context of individual patients. For instance, if the mechanism through which pulmonary rehabilitation reduces problems with dyspnoea is primarily through reduction of anxiety [56, 84], then patients most likely to profit from such interventions are those who have a high emotional response to dyspnoea. Similarly, when symptom intensity increases despite unchanged physiological parameters (e.g. pulmonary function tests, oxygen saturation), the affective dimension of dyspnoea may reveal alternative explanations, as has been hypothesised with respect to "desensitisation" to dyspnoea during pulmonary rehabilitation [57].

\section{Comparison of MDP with other multidimensional instruments}

There are two other recently developed dyspnoea instruments that take account of the multidimensional nature of dyspnoea, the Dyspnoea-12 (D-12) [85-87] and the Cancer Dyspnoea Scale (CDS) [88], but these differ in approach, aiming principally at a summary score, rather than at the separation of different components.

\section{Dyspnoea-12}

The recently developed D-12 questionnaire [85-87] contains several items similar to those in the MDP but the two instruments are different in design, purpose and time frame.

The MDP was designed to examine the separate components of the dyspnoea experience in laboratory and clinical research. The MDP contains one nonspecific item (i.e. A1, the overall "unpleasantness or discomfort of your breathing sensations"). The SQ items were chosen to cover each of the sensory quality modalities known from prior research, providing only one item for each modality. The emotion (A2) items were chosen on the basis of pain research, which measured five primary negative emotions where each negative emotion was represented by a single item. In both laboratory and clinical studies, the MDP asks the subject or patient to focus on how breathing felt at a specific time or event (e.g. "right now", the last $30 \mathrm{~s}$ of the loaded breathing trial, the end of a 6-min walk or when the patient decided to seek emergency care).

In contrast, the D-12 was developed using item-response methods, where items representing differing severity levels along a unidimensional continuum were selected, thus providing a single, numerical breathlessness severity estimate that takes into account the items that are usually most prominent. As appropriate to an instrument designed to produce a single overall score of clinical dyspnoea, some of the sensory terms in the D-12 are nonspecific (i.e. not clearly assigned to a particular modality: e.g. "short of breath", "difficulty catching breath"). Some known dyspnoea modalities described by the SQ items in the 
TABLE 1 Comparison of the Multidimensional Dyspnea Profile (MDP) with Dyspnoea-12 (D-12)

MDP

$\begin{array}{ll}\text { Theoretical } & \text { Empirical } \\ \text { model } & \text { division }\end{array}$

Details
D-12

\begin{tabular}{cc}
\multicolumn{2}{c}{ D-12 } \\
\hline Details & $\begin{array}{c}\text { Empirical } \\
\text { assignment }\end{array}$
\end{tabular}

Refers to how breathing feels at a specific time le.g. "now" or "when Items refer to how breathing you climbed the stairs yesterday") feels "these days"

Item ratings use $0-10$ scales:

A1: $0=$ neutral; $10=$ unbearable

SQ: $0=$ none; $10=$ as intense as $\mid$ can imagine

A2: $0=$ none; $10=$ most $I$ can imagine
Item ratings use four response options: none, mild, moderate or severe

\begin{tabular}{|c|c|c|c|c|}
\hline$A_{1}$ & ID & $\begin{array}{c}\text { Unpleasantness or discomfort of your breathing sensations, how bad } \\
\text { your breathing feels }\end{array}$ & $\begin{array}{l}\text { My breathing is } \\
\text { uncomfortable }\end{array}$ & PA \\
\hline SQ & ID & I am not getting enough air, I am smothering, or I feel hunger for air & $\begin{array}{c}\text { I cannot get enough air } \\
\text { My breath does not go in all } \\
\text { the way }\end{array}$ & $\begin{array}{l}\text { PA } \\
\text { PA }\end{array}$ \\
\hline SQ & ID & My breathing requires muscle work or effort & $\begin{array}{c}\text { My breathing requires more } \\
\text { work }\end{array}$ & PA \\
\hline$S Q$ & ID & I am breathing a lot & No exact match & \\
\hline $\mathrm{SQ}$ & ID & My chest and lungs feel tight or constricted & No exact match & \\
\hline \multirow[t]{2}{*}{ SQ } & ID & My breathing requires mental effort or concentration & No exact match & \\
\hline & & No exact match & My breathing is exhausting & PA \\
\hline $\mathrm{A}_{2}$ & ED & My breathing sensations make me feel depressed & $\begin{array}{l}\text { My breathing makes me feel } \\
\text { depressed }\end{array}$ & $\mathrm{AA}$ \\
\hline $\mathrm{A}_{2}$ & ED & My breathing sensations make me feel anxious & No exact match & \\
\hline $\mathrm{A}_{2}$ & ED & My breathing sensations make me feel frustrated & No exact match & \\
\hline $\mathrm{A}_{2}$ & ED & My breathing sensations make me feel afraid & No exact match & \\
\hline \multirow[t]{2}{*}{$\mathrm{A}_{2}$} & ED & My breathing sensations make me feel angry & No exact match & \\
\hline & & No exact match & $\begin{array}{l}\text { My breathing makes me } \\
\text { agitated }\end{array}$ & $\mathrm{AA}$ \\
\hline
\end{tabular}

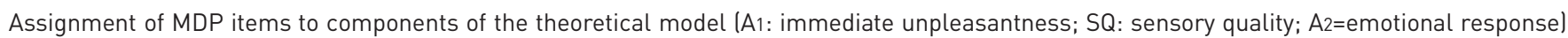
and empirical division in the setting of the emergency department (ID: Immediate Perception Domain; ED: Emotional Response Domain) as well as empirical assignment of D-12 items into two aspects (PA: Physical Aspect; AA: Affective Aspect).

MDP, and some emotions listed in the MDP are not among the D-12 items (e.g. asthmatic "tightness", "anger"). Rather than focussing ratings on a single point in time or episode, the temporal focus of the D-12 is recollection of dyspnoea over an indeterminate recent period ("these days") [85-87]. It does not 
specify activity level. This time frame may be very useful in identifying and tracking dyspnoea in daily life over weeks or months but is not suitable for assessing dyspnoea at a specific time or with a specific activity or intervention.

Despite its underlying unidimensional scaling, post-hoc analysis showed that the D-12 items can be viewed as representing a "physical" (sensory) aspect and an "affective" aspect. This division, with its associated items, is broadly similar to the immediate perception and emotional response domain structure of the MDP shown in post hoc analysis of MDP data from emergency department patients. See table 1 for detailed comparison of the D-12 with the MDP.

\section{Cancer Dyspnoea Scale}

TANAKA et al. [88] have developed and validated in cancer patients the multiple-item CDS, which they label "multidimensional". The 12 items were not selected to measure 12 aspects of dyspnoea that can be aligned with dyspnoea dimensions known from existing evidence. Rather, they were selected from a list of 179 Japanese terms by a group of medical experts using three criteria: understandable, not overlapping and not confounded with other symptoms. The sum score showed a correlation $\left(\mathrm{r}^{2}=0.52\right)$ to a single dimension dyspnoea scale; this finding was confirmed for English and Swedish versions. Although the authors found three factors in factor analysis of the Japanese version, they recognised that "it was difficult to interpret the meaning of each factor on the basis of the wording of the questions alone". They did, however, propose meanings for the three factors (work/effort, anxiety and discomfort) based on very weak correlations $\left(\mathrm{r}^{2}=0.06-0.08\right)$ with other measures (Oncology Physical Status Scale, State-Trait Anxiety Scale and arterial oxygen saturation, respectively). Apart from the anxiety measures, these meanings are difficult to justify on the basis of semantics or our understanding of the physiology of dyspnoea. Although this scale may provide a useful single score, there is no good evidence that it provides useful information on individual dimensions. The time focus of the CDS is "the past few days", similar to the D-12.

\section{Administration of the MDP}

The MDP can be administered by an investigator or healthcare provider, or can be self-completed with an investigator or healthcare provider on hand to answer questions during initial administration. Subjects have rated the MDP highly for clarity, helpfulness and ease of use. In our experience, the questionnaire, including explanations, was usually completed in less than $3 \mathrm{mins}$ on initial use in the laboratory (slightly longer in clinical use), with subsequent administrations taking only 1-2 min for most subjects and patients.

\section{Scoring of the MDP}

The MDP offers the opportunity to investigate the interrelation of the separate dimensions by providing separate measures for 11 important items; these can yield a pattern or profile of dyspnoea responses that can be related to one another, to other measures of sensation or emotion or to clinical and laboratory conditions of interest. Analysis can be at the level of individual items or at the level of the immediate perception and emotional response domains (i.e. the mean of the item scores within each domain) [36]. The immediate global unpleasantness item (A1) is consistent with the leading component of the ATS definition of dyspnoea as "a subjective experience of breathing discomfort"; thus, it is the item most congruent with frequently used unidimensional scales.

\section{Availability of the MDP}

The MDP is copyrighted by the authors. There is no charge for its use, but we request that users inform the authors and cite this article. An approved French translation is available. Investigators wishing to translate the instrument into other languages should contact the authors and will be asked to make the translation available without charge. The complete American English and French versions of the MDP are included in the online supplementary material.

\section{Acknowledgements}

We thank James P. Butler (Harvard Medical School, Boston, MA, USA) and Lewis Adams (Griffith University, Southport, Queensland, Australia) for enlightening discussion on the formation of the underlying ideas. We thank Dora Huang and Victoria Molina (both Beth Israel Deaconess Medical Center, Boston, MA, USA) for editing expertise. The French version of the MDP has been developed and linguistically validated by Mapi Institute, Lyon, France, with the financial support of Pierre Fabre laboratories, and with contributions from Bernard Aguilaniu, Philippe Devillier, Alain Didier, Capucine Morélot-Panzini and Thomas Similowski, for the "Dyspnea" working group of the Société de Pneumologie de Langue Française.

\section{References}

1 Parshall MB, Schwartzstein RM, Adams L, et al. An official American Thoracic Society statement: update on the mechanisms, assessment, and management of dyspnea. Am J Respir Crit Care Med 2012; 185: 435-452.

2 Scano G, Stendardi L, Grazzini M. Understanding dyspnoea by its language. Eur Respir J 2005; 25: 380-385. 
3 Laviolette L, Laveneziana P. Dyspnoea: a multidimensional and multidisciplinary approach. Eur Respir J 2014; 43: 1750-1762.

4 Banzett RB, Pedersen SH, Schwartzstein RM, et al. The affective dimension of laboratory dyspnea: air hunger is more unpleasant than work/effort. Am J Respir Crit Care Med 2008; 177: 1384-1390.

5 Bausewein C, Booth S, Higginson IJ. Measurement of dyspnoea in the clinical rather than the research setting. Curr Opin Support Palliat Care 2008; 2: 95-99.

6 Dorman S, Byrne A, Edwards A. Which measurement scales should we use to measure breathlessness in palliative care? A systematic review. Palliat Med 2007; 21: 177-191.

7 Johnson MJ, Oxberry SG, Cleland JG, et al. Measurement of breathlessness in clinical trials in patients with chronic heart failure: the need for a standardized approach: a systematic review. Eur J Heart Fail 2010; 12: 137-147.

8 Fletcher C. The clinical diagnosis of pulmonary emphysema - an experimental study. Proc Res in Social Med 1952; 45: 577-584.

9 Mahler DA, Weinberg DH, Wells CK, et al. The measurement of dyspnea. Contents, interobserver agreement, and physiologic correlates of two new clinical indexes. Chest 1984; 85: 751-758.

10 Aitken RC. Measurement of feelings using visual analogue scales. Proc R Soc Med 1969; 62: 989-993.

11 Gift AG. Validation of a vertical visual analogue scale as a measure of clinical dyspnea. Rehabil Nurs 1989; 14: 323-325.

12 Adams L, Chronos N, Lane R, et al. The measurement of breathlessness induced in normal subjects: validity of two scaling techniques. Clin Sci (Lond) 1985; 69: 7-16.

13 Gift AG, Narsavage G. Validity of the numeric rating scale as a measure of dyspnea. Am J Crit Care 1998; 7 200-204.

14 Saracino A, Weiland T, Dent A, et al. Validation of a verbal dyspnoea rating scale in the emergency department. Emerg Med Australas 2008; 20: 475-481.

15 Morris NR, Sabapathy S, Adams L, et al. Verbal numerical scales are as reliable and sensitive as visual analog scales for rating dyspnea in young and older subjects. Respir Physiol Neurobiol 2007; 157: 360-365.

16 Borg E, Borg G, Larsson K, et al. An index for breathlessness and leg fatigue. Scand J Med Sci Sports 2010; 20: 644-650.

17 Borg GA. Psychophysical bases of perceived exertion. Med Sci Sports Exerc 1982; 14: 377-381

18 Kendrick KR, Baxi SC, Smith RM. Usefulness of the modified 0-10 Borg scale in assessing the degree of dyspnea in patients with COPD and asthma. J Emerg Nurs 2000; 26: 216-222.

19 Supinski G, Dimarco A, Bark H, et al. Effect of codeine on the sensations elicited by loaded breathing. Am Rev Respir Dis 1990; 141: 1516-1521.

20 O'Donnell DE, Webb KA. Exertional breathlessness in patients with chronic airflow limitation. The role of lung hyperinflation. Am Rev Respir Dis 1993; 148: 1351-1357.

21 Harty HR, Heywood P, Adams L. Comparison between continuous and discrete measurements of breathlessness during exercise in normal subjects using a visual analogue scale. Clin Sci (Lond) 1993; 85: 229-236.

22 Lansing RW, Moosavi SH, Banzett RB. Measurement of dyspnea: word labeled visual analog scale versus verbal ordinal scale. Respir Physiol Neurobiol 2003; 134: 77-83.

23 Fierro-Carrion G, Mahler DA, Ward J, et al. Comparison of continuous and discrete measurements of dyspnea during exercise in patients with COPD and normal subjects. Chest 2004; 125: 77-84.

24 Wilson RC, Jones PW. Long-term reproducibility of Borg scale estimates of breathlessness during exercise. Clin Sci (Lond) 1991; 80: 309-312.

25 Wilson RC, Jones PW. A comparison of the visual analogue scale and modified Borg scale for the measurement of dyspnoea during exercise. Clinical Science 1989; 76: 277-282.

26 Lansing RW, Gracely RH, Banzett RB. The multiple dimensions of dyspnea: review and hypotheses. Respir Physiol Neurobiol 2009; 167: 53-60.

27 Wade JB, Dougherty LM, Archer CR, et al. Assessing the stages of pain processing: a multivariate analytical approach. Pain 1996; 68: 157-167.

28 Price DD. Psychological and neural mechanisms of the affective dimension of pain. Science 2000; 288: 1769-1772.

29 Melzack R. The McGill Pain Questionnaire: major properties and scoring methods. Pain 1975; 1: 277-299.

30 Melzack R, Torgerson WS. On the language of pain. Anesthesiology 1971; 34: 50-59.

31 Gracely RH, Dubner R, McGrath PA. Narcotic analgesia: fentanyl reduces the intensity but not the unpleasantness of painful tooth pulp sensations. Science 1979; 203: 1261-1263.

32 Gracely RH. Evaluation of multi-dimensional pain scales. Pain 1992; 48: 297-300.

33 Gracely RH. Affective dimensions of pain: how many and how measured? APS Journal 1992; 1: 243-247.

34 Price DD, Harkins SW. The affective-motivational dimension of pain: a two-stage model. APS Journal 1992; 1: 229-239.

35 Wade JB, Dougherty LM, Hart RP, et al. A canonical correlation analysis of the influence of neuroticism and extraversion on chronic pain, suffering, and pain behavior. Pain 1992; 51: 67-73.

36 Meek PM, Banzett R, Parshall MB, et al. Reliability and validity of the multidimensional dyspnea profile. Chest 2012; 141: 1546-1553.

37 Melzack R. The short-form McGill pain questionnaire. Pain 1987; 30: 191-197.

38 Melzack R. The McGill Pain questionnaire: from description to measurement. Anesthesiology 2005; 103: 199-202.

39 Elliott MW, Adams L, Cockcroft A, et al. The language of breathlessness. Use of verbal descriptors by patients with cardiopulmonary disease. Am Rev Respir Dis 1991; 144: 826-832.

40 Smith J, Albert P, Bertella E, et al. Qualitative aspects of breathlessness in health and disease. Thorax 2009; 64: 713-718.

41 Banzett RB, Lansing RW, Brown R, et al. "Air hunger" from increased PCO2 persists after complete neuromuscular block in humans. Respir Physiol 1990; 81: 1-17.

42 Banzett RB, Lansing RW, Reid MB, et al. "Air hunger" arising from increased PCO2 in mechanically ventilated quadriplegics. Respir Physiol 1989; 76: 53-67.

43 Simon PM, Schwartzstein RM, Weiss JW, et al. Distinguishable types of dyspnea in patients with shortness of breath. Am Rev Respir Dis 1990; 142: 1009-1014. 
Simon PM, Schwartzstein RM, Weiss JW, et al. Distinguishable sensations of breathlessness induced in normal volunteers. Am Rev Respir Dis 1989; 140: 1021-1027.

Harver A, Mahler DA, Schwartzstein RM, et al. Descriptors of breathlessness in healthy individuals: distinct and separable constructs. Chest 2000; 118: 679-690.

Mahler DA, Harver A, Lentine T, et al. Descriptors of breathlessness in cardiorespiratory diseases. Am J Respir Crit Care Med 1996; 154: 1357-1363.

Parshall MB, Welsh JD, Brockopp DY, et al. Reliability and validity of dyspnea sensory quality descriptors in heart failure patients treated in an emergency department. Heart Lung 2001; 30: 57-65.

Parshall MB. Psychometric characteristics of dyspnea descriptor ratings in emergency department patients with exacerbated chronic obstructive pulmonary disease. Res Nurs Health 2002; 25: 331-344.

Parshall MB, Carle AC, Ice U, et al. Validation of a three-factor measurement model of dyspnea in hospitalized adults with heart failure. Heart Lung 2012; 41: 44-56.

O'Donnell DE, Bertley JC, Chau LK, et al. Qualitative aspects of exertional breathlessness in chronic airflow limitation: pathophysiologic mechanisms. Am J Respir Crit Care Med 1997; 155: 109-115.

O’Donnell DE, Chau LK, Webb KA. Qualitative aspects of exertional dyspnea in patients with interstitial lung disease. J Appl Physiol 1998; 84: 2000-2009.

Banzett RB, Lansing RW, Evans KC, et al. Stimulus-response characteristics of CO2-induced air hunger in normal subjects. Respir Physiol 1996; 103: 19-31.

Parshall MB, Carle AC, Ice U, et al. Validation of a three-factor measurement model of dyspnea in hospitalized adults with heart failure. Heart Lung 2012; 41: 44-56.

McNair DM, Lorr M. An analysis of mood in neurotics. J Abnorm Psychol 1964; 69: 620-627.

Wilson RC, Jones PW. Differentiation between the intensity of breathlessness and the distress it evokes in normal subjects during exercise. Clinical Science 1991; 80: 65-70.

Carrieri-Kohlman V, Donesky-Cuenco D, Park SK, et al. Additional evidence for the affective dimension of dyspnea in patients with COPD. Res Nurs Health 2010; 33: 4-19.

Carrieri-Kohlman V, Gormley JM, Douglas MK, et al. Exercise training decreases dyspnea and the distress and anxiety associated with it. Monitoring alone may be as effective as coaching. Chest 1996; 110: 1526-1535.

Lansing RW, Im BS, Thwing JI, et al. The perception of respiratory work and effort can be independent of the perception of air hunger. Am J Respir Crit Care Med 2000; 162: 1690-1696.

Moosavi SH, Topulos GP, Hafer A, et al. Acute partial paralysis alters perceptions of air hunger, work and effort at constant $\mathrm{P}(\mathrm{CO}(2))$ and $\mathrm{V}(\mathrm{E})$. Respir Physiol 2000; 122: 45-60.

Demediuk BH, Manning H, Lilly J, et al. Dissociation between dyspnea and respiratory effort. Am Rev Respir Dis 1992; 146(5 Pt 1): 1222-1225.

Riley JL, King C. Self-report of alcohol use for pain in a multi-ethnic community sample. J Pain 2009; 10: 944-952.

Gift AG. Psychologic and physiologic aspects of acute dyspnea in asthmatics. Nurs Res 1991; 40: $196-199$.

Gift AG, Plaut SM, Jacox A. Psychologic and physiologic factors related to dyspnea in subjects with chronic obstructive pulmonary disease. Heart Lung 1986; 15: 595-601.

Parshall MB, Meek PM, Sklar D, et al. Test-retest reliability of multidimensional dyspnea profile recall ratings in the emergency department: a prospective, longitudinal study. BMC Emerg Med 2012; 12: 6.

5 Lansing R, Banzett R. Psychophysical methods in the study of respiratory sensation. In: Adams L, Guz A, eds. Respiratory Sensation. New York, Marcel Dekker, 1996; pp. 69-100.

Bausewein C, Farquhar M, Booth S, et al. Measurement of breathlessness in advanced disease: a systematic review. Respir Med 2007; 101: 399-410.

Banzett RB, Adams L, O’Donnell CR, et al. Using laboratory models to test treatment: morphine reduces dyspnea and hypercapnic ventilatory response. Am J Respir Crit Care Med 2011; 184: 920-927.

O’Donnell CR, Schwartzstein RM, Lansing RW, et al. Dyspnea affective response: comparing COPD patients with healthy volunteers and laboratory model with activities of daily living. BMC Pulm Med 2013; 13: 27.

Manning HL, Shea SA, Schwartzstein RM, et al. Reduced tidal volume increases "air hunger" at fixed $\mathrm{PCO}_{2}$ in ventilated quadriplegics. Respir Physiol 1992; 90: 19-30.

Shea SA, Andres LP, Shannon DC, et al. Respiratory sensations in subjects who lack a ventilatory response to $\mathrm{CO}_{2}$. Respir Physiol 1993; 93: 203-219.

Banzett RB, Mulnier HE, Murphy K, et al. Breathlessness in humans activates insular cortex. Neuroreport 2000; 11: $2117-2120$.

2 Evans KC, Banzett RB, Adams L, et al. BOLD fMRI identifies limbic, paralimbic, and cerebellar activation during air hunger. J Neurophysiol 2002; 88: 1500-1511.

Peiffer C, Poline JB, Thivard L, et al. Neural substrates for the perception of acutely induced dyspnea. Am J Respir Crit Care Med 2001; 163: 951-957.

von Leupoldt A, Sommer T, Kegat S, et al. The unpleasantness of perceived dyspnea is processed in the anterior insula and amygdala. Am J Respir Crit Care Med 2008; 177: 1026-1032.

5 Nishino T, Ide T, Sudo T, et al. Inhaled furosemide greatly alleviates the sensation of experimentally induced dyspnea. Am J Respir Crit Care Med 2000; 161: 1963-1967.

6 Bloch-Salisbury E, Binks AP, Banzett RB, et al. Mechanical chest-wall vibration does not relieve air hunger. Respir Physiol Neurobiol 2003; 134: 177-190.

Moosavi SH, Binks AP, Lansing RW, et al. Effect of inhaled furosemide on air hunger induced in healthy humans. Respir Physiol Neurobiol 2007; 156: 1-8.

78 Nishino T, Iiyori N, Isono S, et al. THAM improves an experimentally induced severe dyspnea. J Pain Symptom Manage 2009; 37: 212-219.

79 Banzett R, O'Donnell C, Lansing R, et al. Is the experience of laboratory dyspnea different from wild-type dyspnea in COPD patients? Am J Respir Crit Care Med 2011; 183: A5810.

80 Clark WC, Yang JC, Tsui SL, et al. Unidimensional pain rating scales: a multidimensional affect and pain survey (MAPS) analysis of what they really measure. Pain 2002; 98: 241-247.

81 Moy ML, Lantin ML, Harver A, et al. Language of dyspnea in assessment of patients with acute asthma treated with nebulized albuterol. Am J Respir Crit Care Med 1998; 158: 749-753. 
82 Flaherty KR, Wald J, Weisman IM, et al. Unexplained exertional limitation: characterization of patients with a mitochondrial myopathy. Am J Respir Crit Care Med 2001; 164: 425-432.

83 Schwartzstein R. The language of dyspnea: using verbal clues to diagnose. J Crit Illness 1999; 14: 435-441.

84 Wadell K, Webb KA, Preston ME, et al. Impact of pulmonary rehabilitation on the major dimensions of dyspnea in COPD. COPD 2013; 10: 425-435.

85 Yorke J, Moosavi SH, Shuldham C, et al. Quantification of dyspnoea using descriptors: development and initial testing of the Dyspnoea-12. Thorax 2010; 65: 21-26.

86 Yorke J, Russell AM, Swigris J, et al. Assessment of dyspnea in asthma: validation of The Dyspnea-12. J Asthma 2011; 48: 602-608.

87 Yorke J, Swigris J, Russell AM, et al. Dyspnea-12 is a valid and reliable measure of breathlessness in patients with interstitial lung disease. Chest 2011; 139: 159-164.

88 Tanaka K, Akechi T, Okuyama T, et al. Development and validation of the Cancer Dyspnoea Scale: a multidimensional, brief, self-rating scale. Br J Cancer 2000; 82: 800-805. 